\title{
Indispensable roles of OX40L-derived signal and epistatic genetic effect in immune-mediated pathogenesis of spontaneous pulmonary hypertension
}

Moloud Rabieyousefi ${ }^{1}$, Pejman Soroosh ${ }^{2,7^{*}}$, Kimio Satoh ${ }^{3}$, Fumiko Date ${ }^{1}$, Naoto Ishii ${ }^{2,6}$, Masahiro Yamashita ${ }^{1}$, Masahiko Oka ${ }^{4}$, Ivan F McMurtry ${ }^{4}$, Hiroaki Shimokawa ${ }^{3}$, Masato Nose ${ }^{5}$, Kazuo Sugamura ${ }^{2}$ and Masao Ono ${ }^{1,6^{*}}$

\begin{abstract}
Background: Pulmonary hypertension $(\mathrm{PH})$ refers to a spectrum of diseases with elevated pulmonary artery pressure. Pulmonary arterial hypertension (PAH) is a disease category that clinically presents with severe $\mathrm{PH}$ and that is histopathologically characterized by the occlusion of pulmonary arterioles, medial muscular hypertrophy, and/or intimal fibrosis. PAH occurs with a secondary as well as a primary onset. Secondary PAH is known to be complicated with immunological disorders. The aim of the present study is to histopathologically and genetically characterize a new animal model of PAH and clarify the role of OX40 ligand in the pathogenesis of PAH.

Results: Spontaneous onset of PAH was stably identified in mice with immune abnormality because of overexpression of the tumor necrosis factor (TNF) family molecule OX40 ligand (OX40L). Histopathological and physical examinations revealed the onset of PAH-like disorders in the C57BL/6 (B6) strain of OX40L transgenic mice (B6.TgL). Comparative analysis performed using different strains of transgenic mice showed that this onset depends on the presence of OX40L in the B6 genetic background. Genetic analyses demonstrated a susceptibility locus of a B6 allele to this onset on chromosome 5. Immunological analyses revealed that the excessive OX40 signals in TgL mice attenuates expansion of regulatory T cells the B6 genetic background, suggesting an impact of the B6 genetic background on the differentiation of regulatory $T$ cells.
\end{abstract}

Conclusion: Present findings suggest a role for the OX40L-derived immune response and epistatic genetic effect in immune-mediated pathogenesis of $\mathrm{PAH}$.

\section{Background}

Pulmonary hypertension $(\mathrm{PH})$ is a severe disease condition that can lead to progressive right ventricular failure and ultimately to death. Pulmonary arterial hypertension $(\mathrm{PAH})$ is a major class of $\mathrm{PH}$ defined in the classification of the World Health Organization (WHO). The main histopathological manifestations of $\mathrm{PAH}$ are vasoconstriction, endothelial cell proliferation and fibrosis, smooth-muscle cell proliferation, and thrombosis in small pulmonary

\footnotetext{
*Correspondence: psoroosh@its.jnj.com; onomasao@med.tohoku.ac.jp 'Department of Pathology, Tohoku University Graduate School of Medicine, 2-1 Seiryo, Aoba-ku, Sendai, Miyagi 980-8575 Japan 2Department of Immunology, Tohoku University Graduate School of Medicine, 2-1 Seiryo, Aoba-ku, Sendai, Miyagi 980-8575 Japan Full list of author information is available at the end of the article
}

arteries. These changes result in elevation of pulmonary vascular resistance and, consequently, in pulmonary arterial pressure [1].

PAH occurs as either a primary (idiopathic or familial) or a secondary disease. According to the WHO classification, inflammatory conditions, such as collagen vascular diseases, and viral infections are associated with the occurrence of PAH. Indeed, patients with a subset of idiopathic PAH have some inflammatory disturbances, presented as elevated circulating levels of TNF- $\alpha$, interleukin (IL)-1, and IL-6 [2]. In the case of severe PAH in humans, infiltration of immune cells, including $\mathrm{T}$ cells, B cells, and macrophages, is occasionally observed in pulmonary vascular lesions [3]. Most of the $\mathrm{CD} 4^{+}$and $\mathrm{CD} 8^{+}$ $\mathrm{T}$ cells infiltrating into the intimal lesions have been 
shown to express effector memory T-cell markers, indicating the active status of the T cells. In animal models, augmented expression of IL-18 or administration of IL-6 is sufficient to induce mild spontaneous $\mathrm{PH}[4,5]$. In the former case, IL-13 has been shown to critically mediate inflammatory signals in the lung. Recent studies have proposed that naturally arising $\mathrm{CD} 4{ }^{+} \mathrm{CD} 25^{+}$regulatory $\mathrm{T}$ $\left(\mathrm{T}_{\text {reg }}\right)$ cells, or their mediators, may inhibit the development of experimental PH [6]. Furthermore, it has been suggested that the deficiency of $\mathrm{CD} 4^{+} \mathrm{T}$ cells in humans (e.g., in cases of HIV infection), or the depletion of $\mathrm{CD} 4^{+}$ $\mathrm{T}$ cells in experimental animal models, is associated with the development of PAH [7]. These observations implicate an immune-mediated mechanism in the development of PAH.

Signals through T-cell costimulatory molecules are critically involved in eliciting optimal T-cell functions [8]. OX40 (TNFRSF4, CD134) is a member of the TNF receptor superfamily that is transiently expressed on activated T cells. The ligand of OX40 (OX40L: TNFSF4, CD134L) is mainly expressed on mature antigen-presenting cells as well as on vascular endothelial cells [9-12]. The OX40OX40L interaction is required for optimal effector function of $\mathrm{T}$ cells $[13,14]$ and generation of memory $\mathrm{T}$ cells [15-18]. Recently, growing evidence has unveiled the importance of OX40 signals in the accumulation of effector $\mathrm{CD} 4^{+} \mathrm{T}$ cells at inflammation sites in mouse models of autoimmune diseases. Moreover, a recent study has demonstrated that constitutive OX40-OX40L interactions in OX40L transgenic mice entail spontaneous development of ulcerative colitis-like disease and an undetermined lung disease, which is accompanied by significant production of an anti-DNA antibody [19]. Interestingly, these pathological manifestations have been observed in mice with the C57BL/6 (B6) genetic background but not in those with the BALB/c (BALB) genetic background. The strain-specific pathological manifestations implicate the presence of a genetic predisposition that modulates OX40L-dependent inflammation in the colon and lungs.

The goal of this study was to characterize the undetermined lung disease presented in an OX40L-transgenic B6 strain (B6.TgL) of mice. In the present study, we proposed a new spontaneous model for PAH. Furthermore, this study provided novel insight into the role of the OX40Lderived signal and the genetic predisposition in the immune-mediated pathogenic mechanism of $\mathrm{PAH}$.

\section{Methods}

Mice

Mice with OX40L transgene under the expression control of $l c k$ promoter were generated in a C57BL/6 genetic background as described previously (B6.TgL) [19]. To generate OX40L transgenic mice on BALB/c background
(BALB.TgL), B6.TgL backcrossed to BALB/c strains more than 8 times. Age and sex-matched wild-type $\mathrm{C} 57 \mathrm{BL} / 6$ and $\mathrm{BALB} / \mathrm{c}$ were used as controls. For genetic analyses, TgL mice with mixed genetic background were prepared by the mating of BALB $\times$ B6.TgL and (BALB $\times$ B6) F1 $\times$ B6.TgL. All mice were bred and maintained in conventional clean room in the animal department of the Oriental Bio-service, Co. Ltd, Shizuoka, Japan. In all animal experiments in this study, we followed the Tohoku University guidelines for animal experimentation.

\section{Histopathological examinations}

At 20 weeks of age, each mouse was killed under ether anesthesia. The whole lung was immersion fixed in 10\% formalin in $0.01 \mathrm{M}$ phosphate buffer ( $\mathrm{pH} 7.2$ ), and embedded in paraffin. Tissue sections were stained with hematoxylin and eosin (H\&E) and Masson's trichrome for light-microscopic examination. The disease score of PAH was histopathologically determined. Ten small pulmonary arteries along with terminal bronchioles were individually graded under microscopic examination according to following histopathological criteria: 0, normal; 1 , significant, slight thickening of the media; 2 , thickening of the media with intimal (endothelial) proliferation and/or fibrosis. A mean grade of all points examined was considered as an individual PAH score. Immunohistochemical analyses were performed using the primary antibodies to human $\alpha$-smooth muscle actin ( $\alpha \mathrm{SMA}$ ) (DACO, Tokyo, Japan), which has been shown to react mouse $\alpha$ SMA, and mouse CD31 (Santa Cruz Biotechnology, Santa Cruz, CA).

\section{Right ventricular systolic pressure measurements}

B6, BALB, B6.TgL, and BALB.TgL mice were anesthetized by intraperitoneal injection of ketamine hydrochloride $(60 \mathrm{mg} / \mathrm{kg})$ and xylazine $(8 \mathrm{mg} / \mathrm{kg})$ or, in the second series of measurement using B6, and BALB.TgL mice, pentobarbital sodium $(50 \mathrm{mg} / \mathrm{kg}$ ). Right ventricular systolic pressure (RVSP) was measured in spontaneously breathing mice by direct puncture of the right ventricle with a 25 -gauge needle connected to a pressure transducer [20]. In the second series with the pentobarbital anesthetization, it was measured in artificially ventilated mice with median thoracotomy.

\section{Evaluation of right ventricular hypertrophy}

The hearts isolated from B6, BALB, B6.TgL, and BALB. $\mathrm{TgL}$ mice were fixed in formalin and dissected into right ventricle (RV), left ventricle (LV), and interventricular septum (IVS). The dissected ventricles were carefully washed in saline to remove blood clots and separately weighted. Right ventricular hypertrophy was evaluated by the weight ratio of RV/(LV+IVS). 


\section{Antibodies and flow cytometric analysis}

Anti-CD3-FITC, anti-CD4-allophycocyanin, anti-CD25allophycocyanin, anti-CD44-phycoerythrin (PE), antiCD62L-FITC, and anti-IL-17-PE were purchased from BD Biosciences (San Diego, CA). Anti-mouse Foxp3-PE (FJK$16 \mathrm{~S}$ ) was purchased from eBioscience (San Diego, CA). Anti-mouse $\mathrm{CD} 3 \varepsilon$ (clone 2C11) used for $\mathrm{T}$ cell stimulation and anti-mouse CD16/32 (clone 2.4G2) used for Fc receptor blocking were purified from hybridoma-cultured supernatants in our laboratory. Cells were incubated with antibodies for $30 \mathrm{~min}$ at $4{ }^{\circ} \mathrm{C}$ and then washed to remove unbound antibodies. All the samples were analyzed with a FACSCalibur ${ }^{\mathrm{TM}}$ flow cytometer and the CellQuest ${ }^{\mathrm{TM}}$ program (BD Biosciences).

\section{Preparation of lymphocyte culture and cytokine measurements}

Single-cell suspensions were prepared from spleen and lungs of an 8 to 10 week-old mouse, in which the lung disease of interest is not developed. Lymphocytes in the lung were obtained by digesting minced lung tissues with $150 \mathrm{U} / \mathrm{ml}$ collagenase (Maeda Co. Ltd., Tokyo, Japan) as described previously [21]. The number of effector/memory and regulatory $\mathrm{T}$ cells were calculated based on the percentage of each subpopulation that was $\mathrm{CD} 44^{\text {high }} \mathrm{CD} 62 \mathrm{~L}^{\text {low }}$ and $\mathrm{CD} 4{ }^{+} \mathrm{Foxp}^{+}$, respectively, and the total cell number in each organ. Total lymphocytes isolated from lung tissues that contained equal number of effector/memory $\mathrm{CD} 4^{+} \mathrm{T}$ cells (normalized based on absolute number of effector/memory CD4 T cells) were stimulated with soluble anti-CD3e $(10 \mu \mathrm{g} / \mathrm{ml})$ at $37^{\circ} \mathrm{C}$ for the indicated time. IL-13 levels were assayed in cultured supernatants using ELISA kit for IL-13 (R\&D Systems, Minneapolis, MN), according to the manufacturer's recommendations. The production of IL-17 in lymphocytes was detected by intracellular staining with anti-IL17-PE following incubation of lymphocytes for $4 \mathrm{~h}$ with $50 \mathrm{ng} / \mathrm{ml}$ PMA, $500 \mathrm{ng} / \mathrm{ml}$ Ionomycin (Sigma-Aldrich, St. Louis, MO) in the presence of $10 \mu \mathrm{g} / \mathrm{ml}$ brefeldin A (Invitrogen, Carlsbad, CA).

\section{Genetic mapping}

Genotypes of $\mathrm{BCN} 2$.TgL mice were determined by polymerase chain reaction (PCR) using genomic DNA prepared from the tail tip. The genotyping PCR was performed using standard reagent and the following conditions: $94^{\circ} \mathrm{C}$ for $5 \mathrm{~min}, 35$ cycle of $94^{\circ} \mathrm{C}$ for $30 \mathrm{sec}, 58^{\circ} \mathrm{C}$ for $30 \mathrm{sec}, 72^{\circ} \mathrm{C}$ for $30 \mathrm{sec}$, and final extension $72^{\circ} \mathrm{C}$ for 5 min with the 98 microsatellite markers (additional file 1 ), which represent amplified fragment-length polymorphism between BALB and B6 strains. This genotyping provided full coverage of the mouse autosomes with the marker spaced an average of $12.5 \mathrm{cM}$ apart and a maximum distance of $35 \mathrm{cM}$ between any two markers.
PCR products were visualized with electrophoresis on $2-4 \%$ agarose gels containing $0.01 \%$ ethidium bromide.

In a genome-wide scan, we determined genotypes of the $48 \mathrm{BCN} 2$.TgL mice, which were selected as the top (severest) 24 and the bottom 24 on the list of $\mathrm{PAH}$ score, at all the 98 microsatellite positions (additional file 1). The association at each microsatellite position was evaluated with chi-square test for independence between the genotypes and the two groups that were positive and negative for the incidence of $\mathrm{PAH}$, using standard $2 \times 2$ contingency matrices. A $p$ value less than 0.05 was regarded as suggestive association. The suggestive association was confirmed by the two-tail $t$-test for the difference of means between the two genotype groups of a total of $341 \mathrm{BCN} 2$. TgL mice. In this test a $P$ value less than 0.0034 was regarded as suggestive association. This $\mathrm{P}$ threshold was referred to the previous recommendation [22].

In a linkage mapping, a linkage position was determined with the quantitative trait locus (QTL) program. The logarithm of odd (LOD) was determined with the interval mapping program in the Windows QTL Cartographer (V2.5) software. The PAH scores of all BCN2. TgL mice were used as an indicator of phenotype. A suggestively significant level $(\alpha=0.05)$ of LOD was determined by the permutation test installed in this software (1000 permutations). Map positions (cM) of the microsatellite makers were based on the information of the Mouse Genome Database of The Jackson Laboratory (http://www.informatics.jax.org).

\section{Statistics}

A 95\% confidence interval shown in Table 1 was calculated using the method described previously [23]. The two-tailed $t$-test was used to evaluate a difference of

Table 1 Summary of PAH scores of B6, BALB, and transgenic strains of mice

\begin{tabular}{|c|c|c|c|c|}
\hline Mice* $^{*}$ & $\mathrm{n}+$ & Median of score & $95 \% \mathrm{Cl}$ & Statistics§ \\
\hline B6 & 9 & 0 & $0-0.1$ & \\
\hline BALB & 2 & 0 & n.d. & \\
\hline B6. TgL & 15 & 0.7 & $0.35-1.05$ & 9 \\
\hline BALB. TgL & 8 & 0 & $0-0.1$ & \\
\hline BCF1. TgL & 30 & 0.05 & $0-0.1$ & \\
\hline BCN2. TgL female & 174 & 0.25 & $0.2-0.4$ & 9 \\
\hline BCN2. TgL male & 167 & 0.25 & $0.2-0.4$ & 9 \\
\hline
\end{tabular}

* All mice were killed at 20 week-old for this examination. BCF1, BALB $\times$ B6; BCN2, BCF1 $\times$ B6.TgL.

$\uparrow$ Number of mice tested.

₹ $\mathrm{Cl}$, confidential interval. The $\mathrm{Cl}$ was not determined (n.d.) for BALB/C (BALB). $\S$ The significance of this study was evaluated by Mann-Whitney U-test for the all strains.

ף, $\mathrm{P}<0.01$ (v.s. B6). 
means between two groups. A $P$ value less than 0.05 considered as significant.

\section{Results}

Histopathological characterization of the lung phenotype Microscopic examination revealed diffuse pathological changes in the small- to medium-sized pulmonary arteries in B6.TgL (Figure 1A, E), but not in B6 (Figure 1B), BALB strain of OX40L transgenic mice (BALB.TgL) (Figure 1C), or BALB (Figure 1D). This vascular lesion was found to be readily accompanied with perivascular infiltration of lymphocytes and, to a lesser extent, neutrophils (Figure 1F). These changes were mainly observed in arteries contained in bronchovascular bundles (respiratory arteries) and were typically characterized by fibrocellular endothelial proliferation of the intimal layer and, to a lesser extent, medial muscular hypertrophy (Figure $1 \mathrm{G}$ and $1 \mathrm{H}$ ). Neither muscularization of distal pulmonary arterioles, which is a common pathological change in a hypoxic PAH model, nor plexiform lesions, found in human $\mathrm{PAH}$, were identified. The cells in the intimal lesion were characterized as positive for a myofibroblast marker, smooth musclespecific actin ( $\alpha$ SMA) (Figure 1I), and an endothelial cell marker, CD31 (Figure 1J). When no treatment was administered to avoid vasospasm before the histopathological preparation, vasoconstriction was frequently observed in pulmonary arteries of B6.TgL but not in wild-type B6, BALB, and BALB.TgL mice, irrespective of the presence of the overt pathological changes mentioned above (data not shown). Perivascular lymphocytic infiltration was also observed around pulmonary veins; however, there was no pathologic remodeling in those veins as observed in the
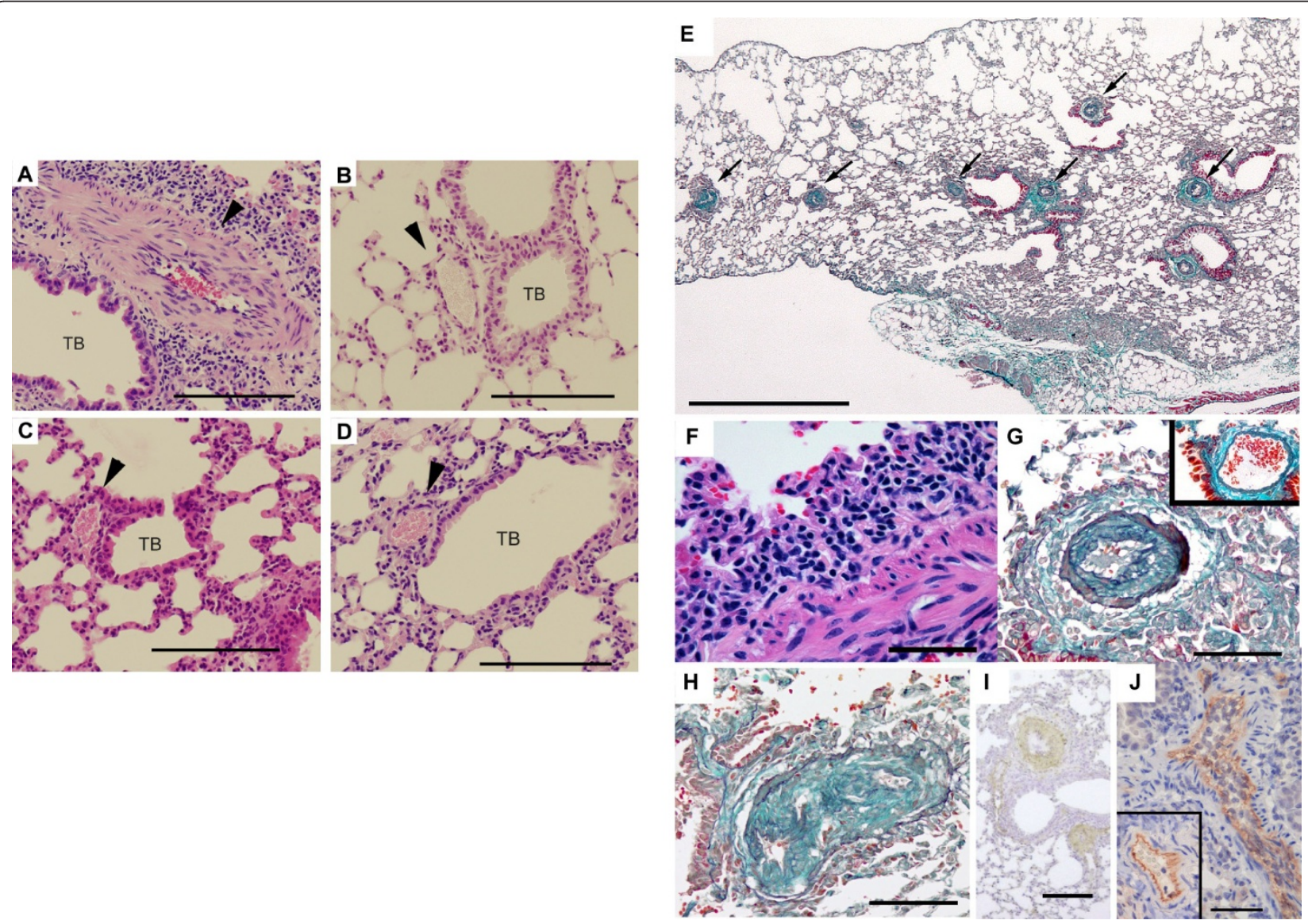

Figure 1 Histopathological features of the lung disease in B6.TgL mice. (A-D) Histopathological manifestation typically present in B6.TgL (A). No pathological manifestation observed in B6 (B), BALB.TgL (C), and BALB (D). The photograms indicated were taken from over 20-week aged male mouse. Arrow heads indicate pulmonary arteries. TB, terminal bronchiole. H\&E staining. Scale bar $=100 \mu m$. (E) Diffuse pathology present in B6.TgL. Masson's trichrome staining. Scale bar $=1 \mathrm{~mm}$. (F) Perivascular lymphocytic infiltration in the affected lung. H\&E staining. Scale bar $=50$ $\mu \mathrm{m} .(\mathrm{G}, \mathrm{H})$ Representative microscopic appearance in the affected arteries in the B6.TgL lung. An inset photogram in $G$ represents the appearance of a normal pulmonary artery. Thickening of the intimal and, to a lesser extent, medial layers with marked intimal fibrosis is characteristic of the affected arteries. Masson's trichrome staining. Scale bar $=100 \mu \mathrm{m}$. I and J, expression of $\alpha$ SMA and CD31 (PECAM), respectively in the thickened arterial wall. The photogram in the inset of $J$ represents a normal manifestation of unaffected artery. Immunohistochemical staining with hematoxylin counter-staining. Scale bar: in I, $200 \mu \mathrm{m}$; in J, $100 \mu \mathrm{m}$. 
arteries (data not shown). Degenerative or granulomatous vascular lesions were not observed in conjunction with the perivascular infiltration, indicating that the vascular lesion of interest is not related to any type of vasculitis syndrome. We found no vascular lesions in the kidney or the colon of B6.TgL mice. Thus, the spontaneous lung disease in B6. $\mathrm{TgL}$ mice was characterized by lung-specific, pulmonary artery-restricted intimal thickening with lymphocytic (chronic) inflammation. These histopathological characteristics are similar yet distinct in a few points from those of human PAH.

\section{Strain-restricted onset of the lung disease}

The PAH-like disease, as defined in the B6.TgL mice, was quantified with a PAH score in other strains of mice, including B6, BALB, BALB.TgL, BALB $\times$ B6.TgL $($ BCF1. $\mathrm{TgL})$, and $(\mathrm{BALB} \times \mathrm{B} 6) \mathrm{F} 1 \times \mathrm{B} 6 . \mathrm{TgL}(\mathrm{BCN} 2 . \mathrm{TgL})$. It was observed that wild-type and different TgL strains, such as BALB.TgL and BCF1.TgL, barely developed the PAH-like disease (Table 1). On the other hand, BCN2.TgL developed a PAH-like disease with a broader distribution of the PAH score than B6.TgL. There were no sex-related differences in the PAH scores (Table 1). These findings indicate that development of the PAH-like disease depends on both the effects of $\mathrm{TgL}$ and on an undefined B6-specific genetic background.

\section{Elevation of RV systolic pressure and RV hypertrophy in B6.TgL}

The PAH-like arteriopathy in B6.TgL mice indicated the onset of clinical $\mathrm{PH}$. We therefore measured right ventricular (RV) systolic pressure (RVSP) in aged B6.TgL, BALB.TgL, and their wild-type strains. RVSP was significantly increased in the B6.TgL mice, as compared to B6 (Figure 2A). Importantly, the RVSP values were significantly correlated with the PAH scores (Figure 2B). Furthermore, significant RV hypertrophy was demonstrated for B6.TgL, as compared to B6 mice (Figure 2C). Increases in RVSP and RV hypertrophy were not observed in the BALB.TgL mice, as compared to B6 mice (additional file 2). In other experiments performed using wildtype BALB mice $(30 \mathrm{w})$, there has been no evidence for RV hypertension or RV hypertrophy in BALB strain: $\mathrm{RVSP}=21.3 \pm 2.72 \mathrm{mmHg}, \mathrm{RV} /(\mathrm{LV}+\mathrm{IVS})=0.25 \pm 0.026$.

\section{Accumulation of effector/memory $\mathrm{CD}^{+} \mathrm{T}$ cells in OX40L-Tg mice}

Previous studies performed with B6.TgL mice have demonstrated a selective increase in the number of $\mathrm{CD} 44^{\text {high }}{ }^{\mathrm{CD}} 62 \mathrm{~L}^{\text {low }}$ effector/memory $\mathrm{CD} 4^{+} \mathrm{T}$ cells in lymphoid and nonlymphoid tissues $[17,19]$. We examined whether the tissue distribution of effector/memory $\mathrm{CD} 4^{+} \mathrm{T}$ cells was altered by the genetic background before the disease onset. Flow cytometric analyses revealed a significant increase in the number of effector/memory $\mathrm{CD} 4^{+} \mathrm{T}$ cells in both the spleen (Figure 3A and 3B) and lungs (Figure $3 \mathrm{C}$ and $3 \mathrm{D}$ ) in every TgL mouse examined. Importantly, this increase was not observed in a strain-specific manner, indicating that the development of $\mathrm{PAH}$ is not simply explained by the increase of effector/memory $\mathrm{CD} 4^{+} \mathrm{T}$ cells.

\section{Strain-specific profile of cytokine production by the lung $\mathrm{CD}^{+} \mathrm{T}$ cells}

The functionality of resident $\mathrm{CD} 4^{+} \mathrm{T}$ cells in the lungs of TgL mice was determined by testing their ability to produce cytokines in response to anti-CD3 or PMA/ionomycin stimulation, respectively. Augmented IL-13 production was observed in the TgL-derived T cells and interestingly, this augmentation was greater in B6.TgL than in BALB. TgL (Figure 4A). Furthermore, a larger number of IL-17producing $\mathrm{CD}_{4}^{+} \mathrm{T}$ cells were observed in B6.TgL mice than in BALB.TgL (Figure 4B). IL-4 and IL-5 were not detected in stimulated lung cells by any strains (data not shown). These results indicate that the function of tissue resident $\mathrm{CD} 4 \mathrm{~T}$ cells can be modulated by the excessive OX40 signals on B6 genetic background before disease onset.

\section{Over-expression of OX40L in B6 background alters the balance between lung resident effector/memory $\mathrm{T}$ cells and regulatory $\mathrm{T}$ cells}

$\mathrm{CD} 4^{+} \mathrm{CD} 25^{+} \mathrm{Foxp}^{+} \mathrm{T}$ cells, usually denoted as $\mathrm{T}_{\text {reg }}$ cells, are known to control inflammatory responses by suppressing the activities of Foxp3- effector T cells [24]. Several independent studies have demonstrated that lung resident $\mathrm{T}_{\text {reg }}$ cells suppress type 2 immune responses and, consequently, reduce pulmonary inflammation [25-27]. We analyzed the population size of $\mathrm{T}_{\text {reg }}$ cells, defined as CD4 ${ }^{+} \mathrm{Foxp}^{+}$, in the lung of non-transgenic and TgL strains. Flow cytometric analyses revealed that the frequency and absolute number of $\mathrm{T}_{\text {reg }}$ cells increased in TgL strains in advance of the disease onset as compared with those in nontransgenic strains (Figure 5A and 5B). It was particularly noted that the increase of $\mathrm{T}_{\text {reg }}$ was less in $\mathrm{B} 6$. TgL than in BALB.TgL, suggesting that B6-specific genetic factors counteract development of $\mathrm{T}_{\text {reg }}$ cells in TgL mice. We also examined the ratio of Foxp3- effector/memory CD4 T cells (additional file 3) to Foxp3+ $\mathrm{T}_{\text {reg }}$ before disease onset. The data shows an increased ratio of effector/memory $\mathrm{T}$ cells to $\mathrm{T}_{\text {reg }}$ cells in the B6.TgL lung compared to the BALB.TgL lung (Figure 5C). These findings also suggest an important role of $\mathrm{T}_{\text {reg }}$ in regulating inflammation associated with the pathogenesis of PAH-like disease in B6. TgL mice.

\section{Identification of a susceptibility locus for PAH}

TgL-dependent PH developed in a strain-specific manner, suggesting that the genetic background had an effect 
A

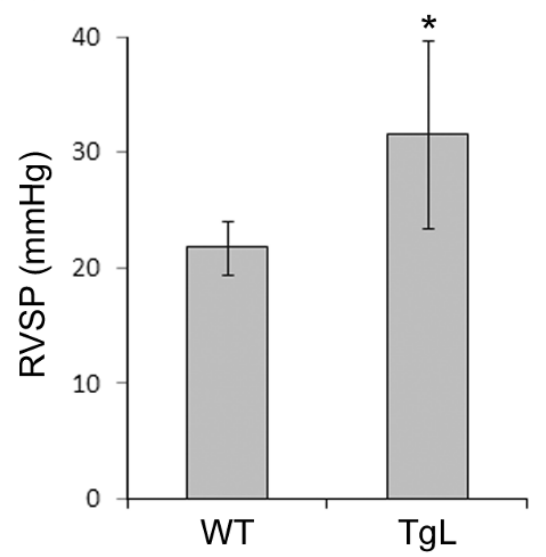

C

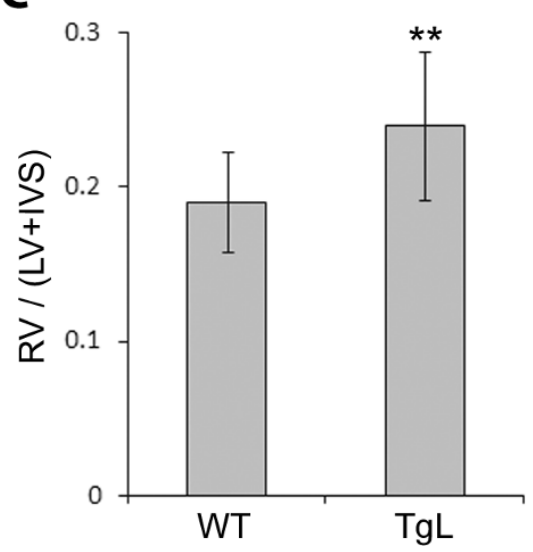

B

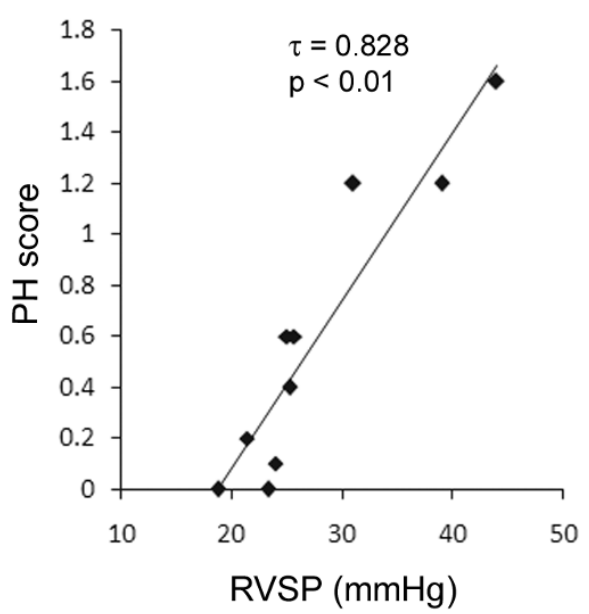

Figure 2 Clinicopathological phenotypes associated with PH. (A) Significant elevation of RVSP ( $\mathrm{mmHg}$ ) in B6.TgL. The result represents a mean \pm standard deviation (SD) of 4 B6 or 6 B6.TgL mice (20 to 24 weeks old) for each group. (B) Correlation between RVSP values and PAH scores obtained from the 10 mice examined in $A$. The significance of this correlation was confirmed with the Kendall tau $(\tau)$ rank correlation coefficient $(\tau=0.828)$. (C) RV hypertrophy manifested in B6.TgL. RV hypertrophy was evaluated with the index provided by the formula, $\mathrm{RV} /(\mathrm{LV}+\mathrm{IVS})$. The result represents a mean \pm SD of $12 \mathrm{~B} 6$ or 8 B6.TgL mice for each group. The significant difference between the two groups was evaluated by two-tailed $t$-test. ${ }^{*}, \mathrm{p}<0.05$; $^{* *}, \mathrm{p}<0.01$.

on the disease phenotypes. To identify a susceptibility locus for a PAH-like disease in B6.TgL, a genetic approach was employed using BCN2.TgL mice, which are descended from the B6.TgL and non-disease-prone BALB.TgL strains of mice. A genome-wide scan performed using selected $48 \mathrm{BCN} 2$. TgL mice identified 4 candidate loci on chromosomes 5, 9, 13, and 17, which were possibly associated with the incidence of a PAH-like disease (additional file 1). The association study with 341 BCN2.TgL mice confirmed the suggestive association at D5Mit346 (1 cM) and D5Mit381 (8 cM) on chromosome 5 (Table 2). The other candidate loci preliminarily defined on chromosomes 9, 13, and 17 were not confirmed by this study. A QTL analysis consistently demonstrated a suggestive linkage between the level of PAH score and the chromosomal region between D5Mit346 and D5Mit381. This linkage was observed in a single LOD peak of 2.4 at $7 \mathrm{cM}$ on chromosome 5 (Figure 6).

\section{Discussion}

Previous studies have shown that B6.TgL mice display abnormal T-cell differentiation and functions, and spontaneous inflammation in the colon and lung. The colonic phenotype in B6.TgL mice was histopathologically defined as an inflammatory bowel disease resembling ulcerative colitis in humans. In the present study, the undetermined lung disease in B6.TgL mice was characterized as a PAH-like disease. PAH is a clinical category of $\mathrm{PH}$ that comprises many different disease entities. Pathological manifestations of the PAH-like disease in B6.TgL mice are not completely parallel to those of idiopathic PAH. The differences between idiopathic PAH 


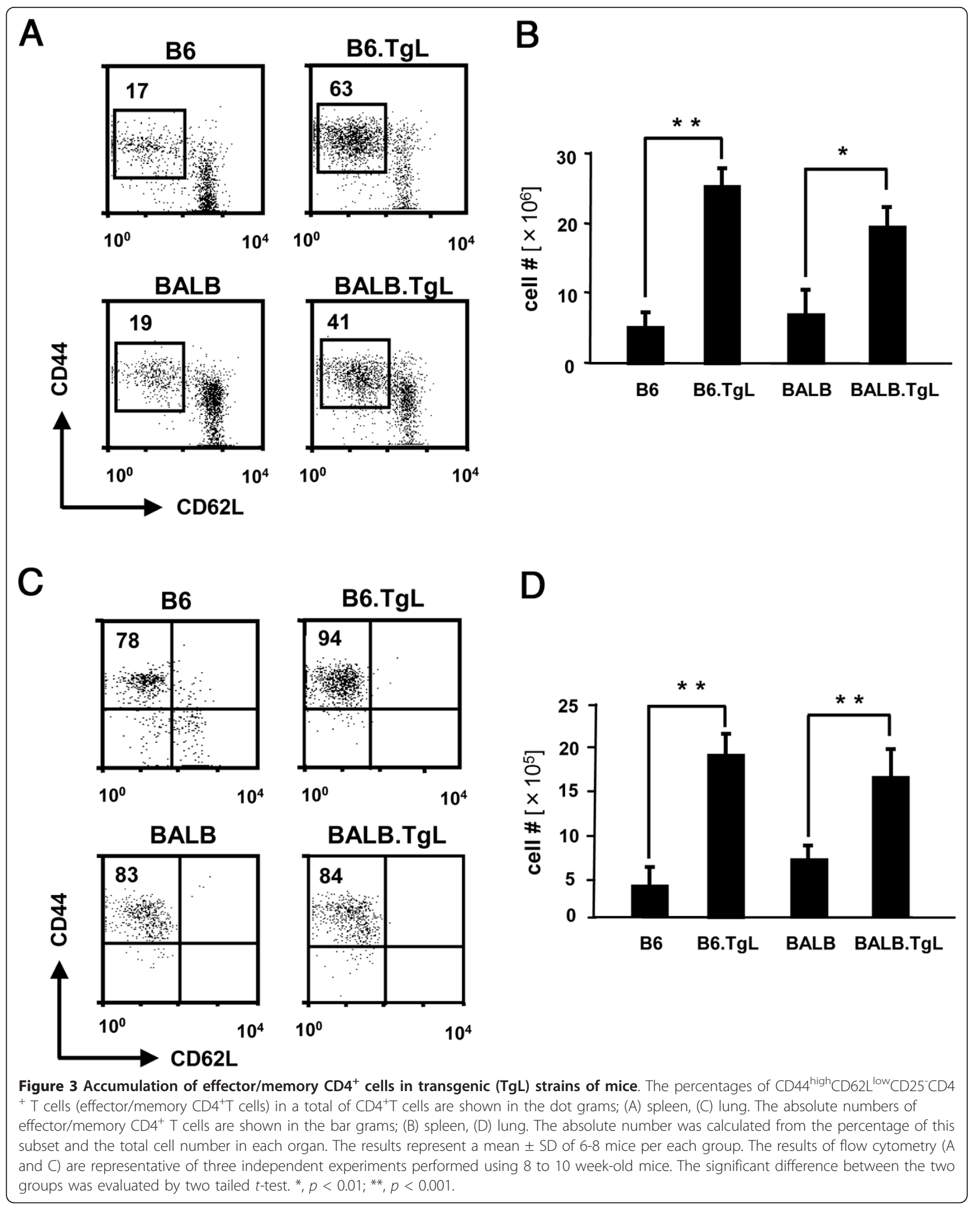




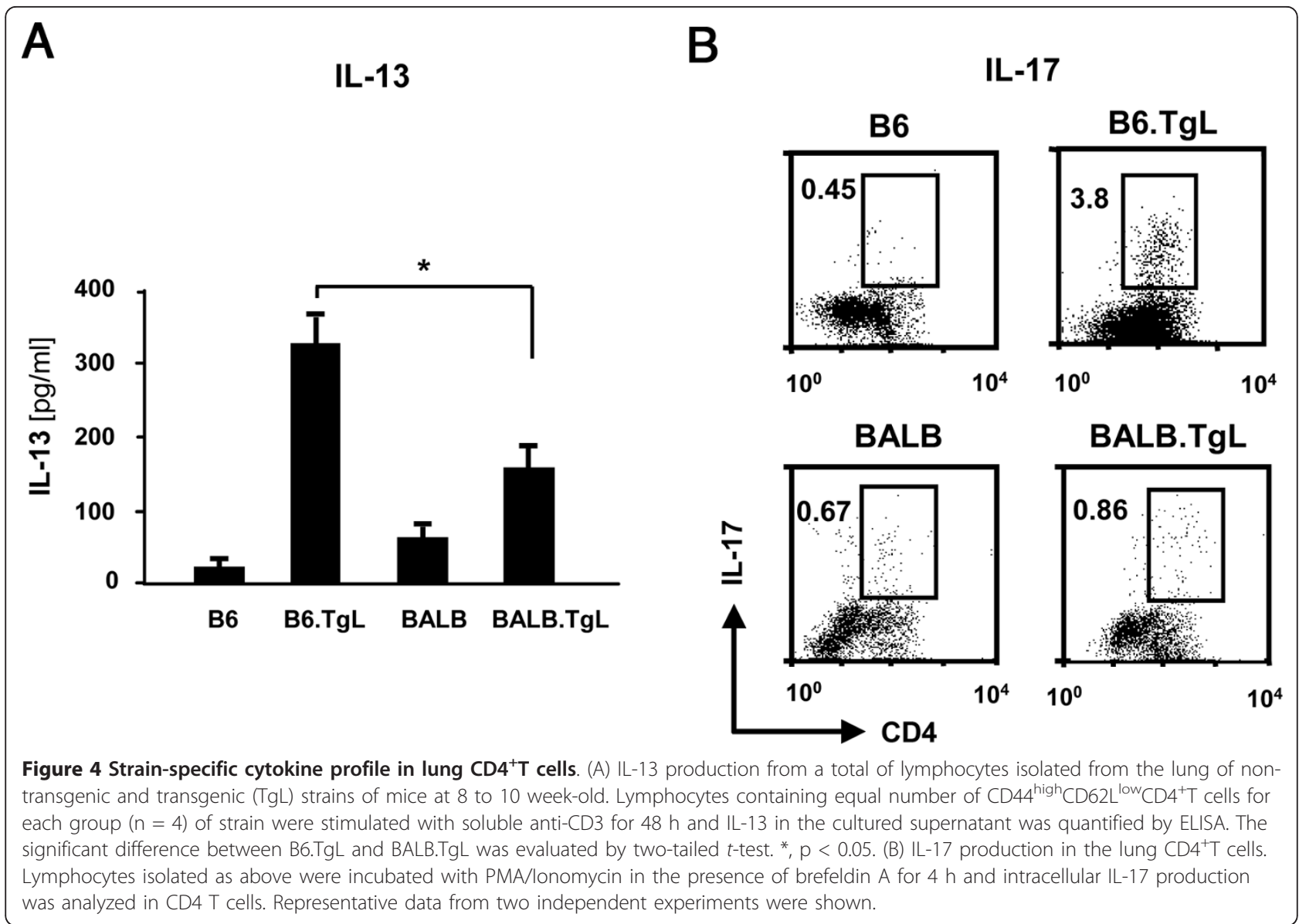

and the present animal model include the caliber of the affected arteries, the primarily affected layer of vascular wall, and the participation of massive lymphocytic perivascular infiltration. Further investigations are needed to define the present lung pathology as any type of PAH. An increasing body of evidence implicates the role of immune-mediated mechanisms in the pathogenesis of $\mathrm{PAH}$. A type of PAH occurs secondarily to collagen vascular disorders, such as systemic sclerosis and mixed connective tissue disease (MCTD). Interestingly, PAH with MCTD presents with a prominent characteristic of endothelial degeneration and proliferation, probably due to the pathogenic contribution of autoantibodies to endothelial cells $[28,29]$. This characteristic may be a pathological consequence of immune-mediated mechanisms shared with the present model. The findings in the B6.TgL mice provide a possible insight into an implication of an OX40L-derived signal in the immunemediated mechanism of endothelial pathology in PAH.

PAH is associated with endothelial cell dysfunction and vasoconstriction. There is no direct evidence for a link between these pulmonary vascular manifestations and abnormality in situ of OX40L-derived signal.
However, it has been shown that OX40L-derived signals have a pathologic impact on the endothelial cell functions of systemic arteries. Recent studies have demonstrated an association of OX40L gene polymorphism with the susceptibility to atherosclerosis in humans [30], and the critical contribution of OX40-OX40L interactions to atherogenesis in low-density lipoprotein receptor-deficient mice [31]. The endothelial cells of the systemic arteries and those of the pulmonary arteries are exposed to different conditions, i.e., blood pressure and oxygen tension. It is interesting to know whether the OX40-OX40L interactions yield a different response on pulmonary endothelial cells than on systemic endothelial cells, and whether the OX40L gene polymorphism is associated with any type of PAH in humans.

Our present immunological studies performed using TgL and non-TgL strains of mice with different genetic backgrounds-B6 and BALB-revealed the respective effects of TgL and strain-dependent genetic background on immune phenotypes in the lung. Previous studies have demonstrated that OX40L-derived signals promote the expansion of effector/memory CD $4^{+} \mathrm{T}$ cells $[17,19]$ 


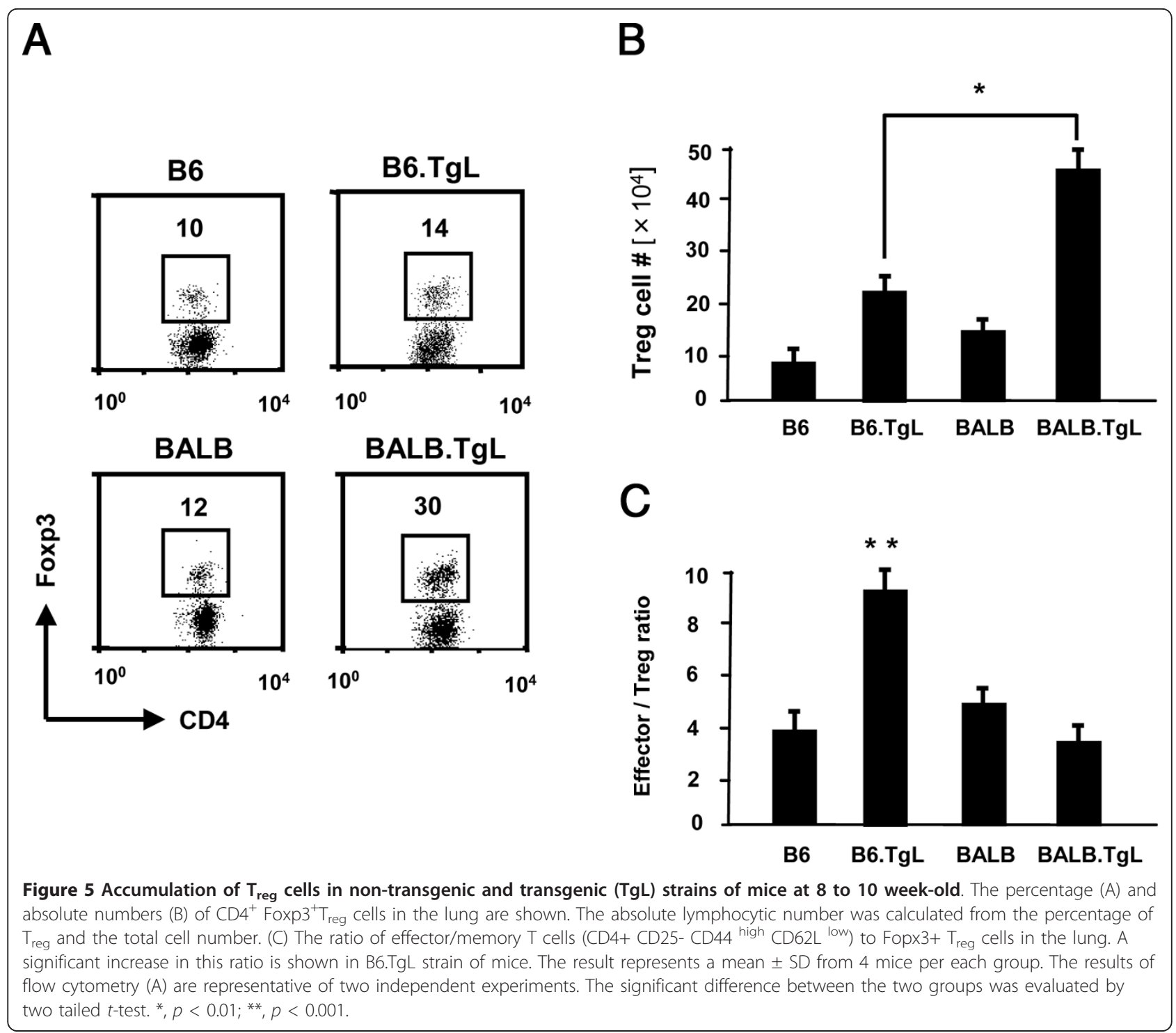

and naturally arising $\mathrm{T}_{\text {reg }}$ cells [32], and enhance the production of IL-13 and IL-17 by CD4 ${ }^{+} \mathrm{T}$ cells [33-35]. To examine which TgL-dependent immune aberrations are correlated with the onset of the PAH-like disease, we examined $\mathrm{TgL}$-dependent immune phenotypes in the lungs of 2 different strains at a pre-disease stage. The findings indicate that B6-specific genetic factors influence the expansion of effector/memory $\mathrm{CD} 4^{+} \mathrm{T}$ cells and $\mathrm{T}_{\text {reg }}$ cells in advance of the onset of lung disease. A possible role of $\mathrm{T}_{\text {reg }}$ cells has been documented in the

Table 2 Genetic association of PAH score in BCN2

\begin{tabular}{lllll}
\hline Marker & Position $(C M)$ & Mean of gradet & Mean of grade & P value $\neq$ \\
\hline D5Mit346 & 1 & $0.51 \pm 0.61(172)$ & $0.32 \pm 0.46(169)$ & $0.0018 \S$ \\
D5Mit381 & 8 & $0.51 \pm 0.59(178)$ & $0.32 \pm 0.46(163)$ & $0.0012 \S$ \\
D5Mit197 & 36 & $0.46 \pm 0.56(192)$ & $0.36 \pm 0.52(149)$ & 0.0844 \\
D5Mit338 & 59 & $0.45 \pm 0.55(191)$ & $0.37 \pm 0.53(150)$ & 0.1476 \\
D5Mit213 & 70 & $0.41 \pm 0.52(192)$ & $0.42 \pm 0.58(149)$ & 0.9149 \\
D5Mit409 & 83 & $0.42 \pm 0.55(165)$ & $0.41 \pm 0.54(178)$ & 0.766 \\
\hline
\end{tabular}

* Values indicate mean $\pm S D$ and the values in parenthesis denote the number of mice.

$+\mathrm{BB}=\mathrm{B} 6$ homozygote; $\mathrm{BC}=\mathrm{B} 6 / \mathrm{BALB}$ heterozygote

₹ The two-tail t-test. §, suggestive linkage [22]. 


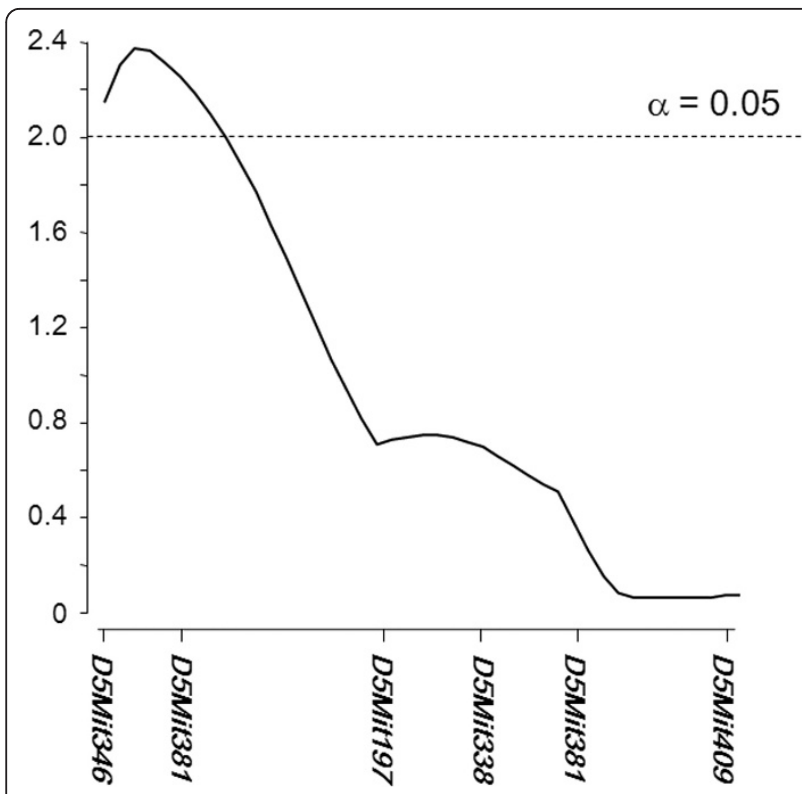

Figure 6 LOD plots of the QTL analysis for PAH scores on chromosome 5 . The significant threshold level $(\alpha=0.05)$ is shown by a score of 2 with a dashed line. The LOD peak (2.4) is located at $7 \mathrm{cM}$. The $\mathrm{Y}$-axis denotes the level of the LOD score, and the $\mathrm{X}$-axis denotes the genetic position defined by the microsatellite markers indicated: D5Mit346 (1 cM), D5Mit381 (8 cM), D5Mit197 (36 cM), D5Mit338 (59 cM), D5Mit213 (70 cM), and D5Mit409 (83 cM). The results were obtained using the interval mapping program of the MapMarker/QTL software.

development of PAH in humans [6]. Furthermore, it is clearly shown that B6-specific genetic factors increase the number of IL-17-producing $\mathrm{CD}^{+}{ }^{+} \mathrm{T}$ cells as well as secretion of IL-13 and IFN $\gamma$ (data not shown) by lung tissue resident $\mathrm{CD} 4^{+} \mathrm{T}$ cells. IL-17 producing CD4 T cells, namely Th17 cells are well known that participates in the pathogenesis of various organ-specific autoimmune diseases, such as inflammatory bowel disease and rheumatoid arthritis [36,37]. Although the role of Th17 cells in $\mathrm{PAH}$ in humans has not been determined, our present findings suggest that they indeed play a role in PAH. IL13 serves as an important mediator in pulmonary inflammation $[5,38,39]$, suggesting a causal contribution of IL13 to the pathogenesis of the present model. The presence of immunological findings provides an insight into $\mathrm{PAH}$-prone immune condition in the lung: the increase of proinflammatory effectors, IL-13 and Th17, and the decrease of an anti-inflammatory effector, $\mathrm{T}_{\text {reg. }}$.

The present genome-wide genetic approach demonstrated a new susceptibility locus controlling the onset of a PAH-like disease in our model. Previous genetic studies performed on familial PAH have shown mutations in 2 genes responsible for susceptibility to $\mathrm{PAH}$ : bone morphogenetic protein receptor 2 gene (BMPR2) [40] and activinlike kinase type-1 gene $(A L K-1)$ [41]. Our identified locus includes neither of these genes, nor, to the best of our knowledge, any gene involved in their signal transduction pathways. However, Nos3 and $H g f$ genes were particularly noted within this locus. Nitric oxide (NO) is known as a potent endothelial cell-derived vasodilator and an inhibitor of smooth muscle proliferation. Endothelial NO production largely depends on NOS3/eNOS (encoded by Nos3). NOS3-deficient mice showed reduced pulmonary vascular proliferation and remodeling to chronic hypoxia $[42,43]$. Several studies have reported the preventive role of $\mathrm{NO}$ in the development of $\mathrm{PH}$ in mice and humans. The polymorphism of human Nos3 gene is associated with highaltitude pulmonary edema and $\mathrm{PH}$ in patients with chronic obstructive pulmonary disease [44]. On the other hand, $H g f$, which encodes hepatocyte growth factor (HGF), suppresses vascular medial hyperplasia and matrix accumulation in advanced $\mathrm{PH}$ in rats [45]. These findings have underscored the role of NOS3/eNOS or HGF as a pathogenic modifier in the present $\mathrm{PH}$ model.

A T-cell subset, type II helper T cell (Th2), plays an important role in the pathogenesis of PAH in mice [39]. In this regard, it is noteworthy that the 2 loci (the transgene locus and the susceptibility locus) have a strong impact on Th1/Th2 balance. The OX40 signal promotes a Th2-prone condition in mice [34]. On the other hand, NO and HGF serve as inducible factors for type I helper T cells (Th1) [46,47]. Therefore, in the TgL strains of mice, the 2 loci are mutually counterbalanced, and the net Th1/Th2 proportion depends mainly on the polymorphic effect of the susceptibility locus. In a B6 genetic background, an effect of the susceptibility locus may suppress Th1 responses and maximize Th2 augmentation in the lung conferred by the OX40L transgene, resulting in the B6-specific onset of $\mathrm{PH}$.

\section{Conclusion}

The present study reported a novel transgenic mouse model for PH. This model differs from previous $\mathrm{PH}$ models, which include a hypoxia-induced model, a drug-induced model, and a genetic model (i.e., endothelin B receptor-deficient) [48], in etiology, histopathology, and spontaneity of $\mathrm{PH}$. Considering the physiological functions of OX40L, it is likely that the development of $\mathrm{PH}$ in the present model depends on Th2-mediated mechanisms. The present model may provide a new experimental opportunity for investigating immunemediated mechanisms underlying $\mathrm{PAH}$ and the development of immune-targeted therapy for PAH.

\section{Additional material}

Additional file 1: Summary of genome wide scan. Genotypes of $B C N 2 . T g L$ mice were determined by polymerase chain reaction (PCR) using genomic DNA for 98 microsatellite positions. 
Additional file 2: Pathological phenotypes in the lung of BALB.TgL mice. (A) RVSP $(\mathrm{mmHg})$ in BALB.TgL ( $35 \mathrm{w}$, male, $\mathrm{n}=4$ ) and wild-type B6 ( $28 w$, male, $n=4)$. The difference in the average values between the two strains is not statistically significant ( $p=0.37$, two tailed $t$ test). These RVSP values tended to be lower than those in our previous measurement shown in Figure 2A. This change is probably due to the difference in the experimental conditions. (B) Evaluation of RV hypertrophy in BALB.TgL ( $35 \mathrm{w}$, male, $\mathrm{n}=5$ ) and wild-type B6 (28 w, male, $n=5)$. RV hypertrophy was evaluated with the index of RV/(LV + IVS). The difference between the two strains is not statistically significant ( $p=0.76$, two-tailed t-test).

Additional file 3: Foxp3 expression on total CD4 versus CD25 negative effector CD4 T cells. Total CD4 and CD4+CD62L ${ }^{\text {low }} C D 25$ negative cells from the lung tissue were stained for intracellular Foxp3.

\section{List of Abbreviations}

aSMA: Alpha smooth muscle actin; B6.TgL: OX40L transgenic on C75BL/6 strain; BALB. TgL: OX4OL transgenic on BALB/C strain; H \& E: Hematoxylin and Eosin; HGF: Hepatocyte growth factor; IVS: Intraventricular Septum; LOD: Logarithm of odd; LV: Left ventricular; MCTD: Mixed connective tissue disease; NO: Nitric oxide; OX40L: OX40 ligand; PH: Pulmonary hypertension; PAH: Pulmonary arterial hypertension; PMA: phorbol 12-myristate 13-acetate; QTL: quantitative trait locus; RV: Right ventricle; RVSP: Right ventricular systolic pressure; Th: T helper cells; T reg: regulatory T cell; TNFSF: Tumor necrosis super-family

\section{Acknowledgements}

We would like to thank Drs. Mingcai Zhang, Hiroshi Furukawa, Hiroyuki Kumagai, Shigeki Shibahara, Yasushi Hoshikawa, and Masahisa Kyogoku for providing helpful, critical comments, Mr. Shin-ichi Tanaka and Miss Naomi Yamaki for technical help in the RVSP measurement, and Mrs. Emi Yura for secretarial help. This work was supported by grants: No.19390108 \& No.19659096, Grants-in-Aid for Scientific Research from the Ministry of Education, Science, Sports, and Culture of Japan. CREST, JST.

\section{Author details}

'Department of Pathology, Tohoku University Graduate School of Medicine, 2-1 Seiryo, Aoba-ku, Sendai, Miyagi 980-8575 Japan. ${ }^{2}$ Department of Immunology, Tohoku University Graduate School of Medicine, 2-1 Seiryo, Aoba-ku, Sendai, Miyagi 980-8575 Japan. ${ }^{3}$ Department of Cardiovascular Medicine, Tohoku University Graduate School of Medicine, 2-1 Seiryo, Aobaku, Sendai, Miyagi 980-8575 Japan. ${ }^{4}$ Department of Pharmacology and Medicine and Center for Lung Biology, University of South Alabama, College of Medicine, 307 University Blvd N Mobile, AL 36688-0002 USA. ${ }^{5}$ Department of Pathology, Ehime University Graduate School of Medicine, Shitsukawa, Toon, Ehime 791-0295 Japan. ${ }^{6} J a p a n$ Science and Technology Agency, CREST, Tokyo, Japan. ${ }^{7}$ Johnson \& Johnson Pharmaceutical Research \& Development, L.L.C., 3210 Merryfield Row, San Diego, California 92121, USA.

\section{Authors' contributions}

$\mathrm{MR}$ and $\mathrm{MO}(\mathrm{Ono})$ conceived the project and contributed to all the aspect of this research. MN contributed to the genetic findings. MY, MO (Oka), and IFM contributed to histopathological findings. PS, NI, and KS (Sugamura) contributed to immunological findings. KS (Satoh) and HS contributed to physical findings such as blood pressure measurements. All authors read and approved the final manuscript.

\section{Competing interests}

The authors declare that they have no competing interests.

Received: 16 June 2011 Accepted: 15 December 2011 Published: 15 December 2011

\section{References}

1. Veeraraghavan S, Koss MN, Sharma OP: Pulmonary veno-occlusive disease. Curr Opin Pulm Med 1999, 5(5):310-313.

2. Dorfmuller P, Perros F, Balabanian K, Humbert M: Inflammation in pulmonary arterial hypertension. Eur Respir J 2003, 22(2):358-363.
3. Humbert M, Morrell NW, Archer SL, Stenmark KR, MacLean MR, Lang IM, Christman BW, Weir EK, Eickelberg O, Voelkel NF, et al: Cellular and molecular pathobiology of pulmonary arterial hypertension. J Am Coll Cardiol 2004, 43(12 Suppl S):13S-24S.

4. Golembeski SM, West J, Tada Y, Fagan KA: Interleukin-6 causes mild pulmonary hypertension and augments hypoxia-induced pulmonary hypertension in mice. Chest 2005, 128(6 Suppl):572S-573S.

5. Hoshino T, Kato S, Oka N, Imaoka H, Kinoshita T, Takei S, Kitasato Y, Kawayama T, Imaizumi T, Yamada K, et al: Pulmonary Inflammation and Emphysema: Role of the Cytokines IL-18 and IL-13. Am J Respir Crit Care Med 2007, 176(1):49-62.

6. Nicolls MR, Taraseviciene-Stewart L, Rai PR, Badesch DB, Voelkel NF: Autoimmunity and pulmonary hypertension: a perspective. Eur Respir $J$ 2005, 26(6):1110-1118.

7. Taraseviciene-Stewart L, Nicolls MR, Kraskauskas D, Scerbavicius R, Burns N, Cool C, Wood K, Parr JE, Boackle SA, Voelkel NF: Absence of T cells confers increased pulmonary arterial hypertension and vascular remodeling. Am J Respir Crit Care Med 2007, 175(12):1280-1289.

8. Lenschow DJ, Walunas TL, Bluestone JA: CD28/B7 system of T cell costimulation. Annu Rev Immunol 1996, 14:233-258.

9. Croft M: Co-stimulatory members of the TNFR family: keys to effective T-cell immunity? Nat Rev Immunol 2003, 3(8):609-620.

10. Sugamura K, Ishii N, Weinberg AD: Therapeutic targeting of the effector T-cell co-stimulatory molecule OX40. Nat Rev Immunol 2004, 4(6):420-431.

11. Mestas J, Crampton SP, Hori T, Hughes CC: Endothelial cell co-stimulation through OX40 augments and prolongs $\mathrm{T}$ cell cytokine synthesis by stabilization of cytokine mRNA. Int Immunol 2005, 17(6):737-747.

12. Kotani A, Hori T, Matsumura Y, Uchiyama T: Signaling of gp34 (OX40 ligand) induces vascular endothelial cells to produce a CC chemokine RANTES/CCL5. Immunol Lett 2002, 84(1):1-7.

13. Gramaglia I, Weinberg AD, Lemon M, Croft M: Ox-40 ligand: a potent costimulatory molecule for sustaining primary CD4 T cell responses. J Immunol 1998, 161(12):6510-6517.

14. Murata K, Ishii N, Takano H, Miura S, Ndhlovu LC, Nose M, Noda T, Sugamura K: Impairment of antigen-presenting cell function in mice lacking expression of OX40 ligand. J Exp Med 2000, 191(2):365-374.

15. Rogers PR, Song J, Gramaglia I, Killeen N, Croft M: OX40 promotes Bcl-xL and $\mathrm{BCl}-2$ expression and is essential for long-term survival of CD4 T cells. Immunity 2001, 15(3):445-455.

16. Soroosh $\mathrm{P}$, Ine $\mathrm{S}$, Sugamura $\mathrm{K}$, Ishii N: OX40-OX40 ligand interaction through T cell-T cell contact contributes to CD4 T cell longevity. J Immunol 2006, 176(10):5975-5987.

17. Soroosh $\mathrm{P}$, Ine $\mathrm{S}$, Sugamura $\mathrm{K}$, Ishii $\mathrm{N}$ : Differential Requirements for $\mathrm{OX} 40$ Signals on Generation of Effector and Central Memory CD4+ T Cells. J Immunol 2007, 179(8):5014-5023.

18. Maxwell JR, Weinberg A, Prell RA, Vella AT: Danger and OX40 receptor signaling synergize to enhance memory $T$ cell survival by inhibiting peripheral deletion. J Immunol 2000, 164(1):107-112.

19. Murata K, Nose M, Ndhlovu LC, Sato T, Sugamura K, Ishii N: Constitutive OX40/OX40 ligand interaction induces autoimmune-like diseases. J Immunol 2002, 169(8):4628-4636.

20. Satoh K, Kagaya Y, Nakano M, Ito Y, Ohta J, Tada H, Karibe A, Minegishi N, Suzuki N, Yamamoto M, et al: Important role of endogenous erythropoietin system in recruitment of endothelial progenitor cells in hypoxia-induced pulmonary hypertension in mice. Circulation 2006, 113(11):1442-1450.

21. Marzo AL, Vezys V, Williams K, Tough DF, Lefrancois L: Tissue-level regulation of Th1 and Th2 primary and memory CD4 T cells in response to Listeria infection. J Immunol 2002, 168(9):4504-4510.

22. Lander $E$, Kruglyak $L$ : Genetic dissection of complex traits: guidelines for interpreting and reporting linkage results. Nat Genet 1995, 11(3):241-247.

23. Morris JA, Gardner MJ: Calculating confidence intervals for relative risks (odds ratios) and standardised ratios and rates. Br Med J (Clin Res Ed) 1988, 296(6632):1313-1316.

24. Sakaguchi S: Naturally arising CD4+ regulatory t cells for immunologic self-tolerance and negative control of immune responses. Annu Rev Immunol 2004, 22:531-562.

25. Hadeiba H, Locksley RM: Lung CD25 CD4 regulatory T cells suppress type 2 immune responses but not bronchial hyperreactivity. J Immunol 2003, 170(11):5502-5510 
26. Lewkowich IP, Herman NS, Schleifer KW, Dance MP, Chen BL, Dienger KM, Sproles AA, Shah JS, Kohl J, Belkaid Y, et al: CD4+CD25+ T cells protect against experimentally induced asthma and alter pulmonary dendritic cell phenotype and function. J Exp Med 2005, 202(11):1549-1561.

27. McKinley L, Logar AJ, McAllister F, Zheng M, Steele C, Kolls JK: Regulatory T cells dampen pulmonary inflammation and lung injury in an animal model of pneumocystis pneumonia. J Immunol 2006, 177(9):6215-6226.

28. Bodolay E, Csipo I, Gal I, Sipka S, Gyimesi E, Szekanecz Z, Szegedi G: Antiendothelial cell antibodies in mixed connective tissue disease: frequency and association with clinical symptoms. Clin Exp Rheumatol 2004, 22(4):409-415.

29. Vegh J, Szodoray P, Kappelmayer J, Csipo I, Udvardy M, Lakos G, Aleksza M, Soltesz P, Szilagyi A, Zeher M, et al: Clinical and immunoserological characteristics of mixed connective tissue disease associated with pulmonary arterial hypertension. Scand J Immunol 2006, 64(1):69-76.

30. Wang X, Ria M, Kelmenson PM, Eriksson P, Higgins DC, Samnegard A, Petros C, Rollins J, Bennet AM, Wiman B, et al: Positional identification of TNFSF4, encoding OX40 ligand, as a gene that influences atherosclerosis susceptibility. Nat Genet 2005, 37(4):365-372.

31. van Wanrooij EJ, van Puijvelde GH, de Vos P, Yagita $H$, van Berkel TJ, Kuiper J: Interruption of the Tnfrsf4/Tnfsf4 (OX40/OX40L) pathway attenuates atherogenesis in low-density lipoprotein receptor-deficient mice. Arterioscler Thromb Vasc Biol 2007, 27(1):204-210.

32. Takeda I, Ine S, Killeen N, Ndhlovu LC, Murata K, Satomi S, Sugamura K, Ishii N: Distinct roles for the OX40-OX40 ligand interaction in regulatory and nonregulatory T cells. J Immunol 2004, 172(6):3580-3589.

33. Ohshima $Y$, Yang LP, Uchiyama T, Tanaka $Y$, Baum $P$, Sergerie $M$, Hermann P, Delespesse G: OX40 costimulation enhances interleukin-4 (IL4) expression at priming and promotes the differentiation of naive human CD4(+) T cells into high IL-4-producing effectors. Blood 1998, 92(9):3338-3345.

34. Hoshino A, Tanaka Y, Akiba H, Asakura Y, Mita Y, Sakurai T, Takaoka A, Nakaike S, Ishii N, Sugamura K, et al: Critical role for OX40 ligand in the development of pathogenic Th2 cells in a murine model of asthma. Eur $\mathrm{J}$ Immunol 2003, 33(4):861-869.

35. Nakae $S$, Saijo $S$, Horai $R$, Sudo $K$, Mori $S$, Iwakura $Y$ : IL-17 production from activated $T$ cells is required for the spontaneous development of destructive arthritis in mice deficient in IL-1 receptor antagonist. Proc Natl Acad Sci USA 2003, 100(10):5986-5990.

36. Kotake S, Udagawa N, Takahashi N, Matsuzaki K, Itoh K, Ishiyama S, Saito S, Inoue K, Kamatani N, Gillespie MT, et al: IL-17 in synovial fluids from patients with rheumatoid arthritis is a potent stimulator of osteoclastogenesis. J Clin Invest 1999, 103(9):1345-1352.

37. Fujino S, Andoh A, Bamba S, Ogawa A, Hata K, Araki Y, Bamba T, Fujiyama $Y$ : Increased expression of interleukin 17 in inflammatory bowel disease. Gut 2003, 52(1):65-70.

38. Zhu Z, Ma B, Zheng T, Homer RJ, Lee CG, Charo IF, Noble P, Elias JA: IL-13induced chemokine responses in the lung: role of CCR2 in the pathogenesis of IL-13-induced inflammation and remodeling. J Immunol 2002, 168(6):2953-2962.

39. Daley E, Emson C, Guignabert C, de Waal Malefyt R, Louten J, Kurup VP, Hogaboam C, Taraseviciene-Stewart L, Voelkel NF, Rabinovitch M, et al: Pulmonary arterial remodeling induced by a Th2 immune response. $J$ Exp Med 2008, 205(2):361-372.

40. Deng Z, Morse JH, Slager SL, Cuervo N, Moore KJ, Venetos G, Kalachikov S, Cayanis E, Fischer SG, Barst RJ, et al: Familial primary pulmonary hypertension (gene PPH1) is caused by mutations in the bone morphogenetic protein receptor-II gene. Am J Hum Genet 2000, 67(3):737-744.

41. Morse JH, Deng Z, Knowles JA: Genetic aspects of pulmonary arterial hypertension. Ann Med 2001, 33(9):596-603.

42. Quinlan TR, Li D, Laubach VE, Shesely EG, Zhou N, Johns RA: eNOSdeficient mice show reduced pulmonary vascular proliferation and remodeling to chronic hypoxia. Am J Physiol Lung Cell Mol Physiol 2000, 279(4):L641-650

43. Steudel W, Scherrer-Crosbie M, Bloch KD, Weimann J, Huang PL, Jones RC, Picard MH, Zapol WM: Sustained pulmonary hypertension and right ventricular hypertrophy after chronic hypoxia in mice with congenital deficiency of nitric oxide synthase 3. J Clin Invest 1998, 101(11):2468-2477.

44. Droma Y, Hanaoka M, Ota M, Katsuyama Y, Koizumi T, Fujimoto K Kobayashi T, Kubo K: Positive association of the endothelial nitric oxide synthase gene polymorphisms with high-altitude pulmonary edema. Circulation 2002, 106(7):826-830

45. Ono M, Sawa Y, Mizuno S, Fukushima N, Ichikawa H, Bessho K, Nakamura T, Matsuda $\mathrm{H}$ : Hepatocyte growth factor suppresses vascular medial hyperplasia and matrix accumulation in advanced pulmonary hypertension of rats. Circulation 2004, 110(18):2896-2902.

46. Ito W, Kanehiro A, Matsumoto K, Hirano A, Ono K, Maruyama H, Kataoka M, Nakamura T, Gelfand EW, Tanimoto M: Hepatocyte growth factor attenuates airway hyperresponsiveness, inflammation, and remodeling. Am J Respir Cell Mol Biol 2005, 32(4):268-280.

47. Niedbala W, Wei XQ, Campbell C, Thomson D, Komai-Koma M, Liew FY: Nitric oxide preferentially induces type $1 \mathrm{~T}$ cell differentiation by selectively up-regulating IL-12 receptor beta 2 expression via CGMP. Proc Natl Acad Sci USA 2002, 99(25):16186-16191.

48. Ivy DD, McMurtry IF, Colvin K, Imamura M, Oka M, Lee DS, Gebb S, Jones PL: Development of occlusive neointimal lesions in distal pulmonary arteries of endothelin B receptor-deficient rats: a new model of severe pulmonary arterial hypertension. Circulation 2005, 111(22):2988-2996

doi:10.1186/1471-2172-12-67

Cite this article as: Rabieyousefi et al.: Indispensable roles of OX40Lderived signal and epistatic genetic effect in immune-mediated pathogenesis of spontaneous pulmonary hypertension. BMC Immunology 2011 12:67.

\section{Submit your next manuscript to BioMed Central and take full advantage of:}

- Convenient online submission

- Thorough peer review

- No space constraints or color figure charges

- Immediate publication on acceptance

- Inclusion in PubMed, CAS, Scopus and Google Scholar

- Research which is freely available for redistribution

Submit your manuscript at www.biomedcentral.com/submit
C Biomed Central 